\title{
Wind Tunnel Research on the Unmanned Aerial Vehicle Rotor Blade Setting Angle
}

\section{Ksenia Siadkowska'}

1 Department of Thermodynamics, Fluid Mechanics and Aviation Propulsion Systems, Faculty of Mechanical Engineering, Lublin University of Technology, Nadbystrzycka 38D, 20-618 Lublin, Poland

e-mail: k.siadkowska@pollub.pl

\begin{abstract}
The recommended optimal twist angles were determined for particular sections of the prototype rotor blade dedicated to an unmanned helicopter. The main rotor blade was tested in the GUNT HM 170 tunnel for four different air flow velocities and variable angles of attack. The blade model was divided into sections, each of them was made in the 3D printing technology. For all the sections, the maximum lift and drag forces were determined and then converted to dimensionless values. The aerodynamic characteristics were calculated for each section and different air flow velocities in the wind tunnel. Due to the division of the blade into sections, it was possible to define the most favorable angles of attack along the rotor radius. Aerodynamic excellence was identified for each blade section and air flow velocities.
\end{abstract}

Keywords: wind tunnel; thermoanemometer; rotor blade; aerodynamic coefficient; UAV

\section{INTRODUCTION}

Rotor blades should be shaped so that the maximum lift force can be achieved with the lowest possible drag force under the specified conditions. The blade twist angle is one of the factors behind the amount of the lift force generated by the aircraft rotor. The aircraft shape can be changed in various ways $[1,5,8,12,14$, 32]. Modifications of main rotors and blades are frequently investigated [15, 16, 21, 22, 23, 24]. Fan blades with shape memory alloy strips are examined in the paper [9]. The shape of these blades was changed by the flow temperature in a specially designed wind tunnel. The studies showed the possibility of a passive control of a car fan. The authors underlined that the materials with shape memory are gaining popularity due to high energy density and their compact design. The attention was focused on the especially attractive use of intelligent materials to improve the aerodynamic performance because other elements hindering the flow are eliminated. There are known studies on adaptive elements in helicopter blades [6], wind turbines [17] and aircraft wings [2]. The paper [6] describes the concept of using the wires made of shape memory materials as the elements strengthening a supporting structure of helicopter blades. The paper [17] focuses on the previous research and the consequences of using intelligent materials, especially a reduction of the aerodynamic drag of blades, reduction of noise and vibrations, but also the possibility of turbulence. The potential to reduce the torsional loads of helicopter blades with piezoelectric actuators by $10 \%$ was pointed out there. No moving elements, simplified designs and reduced vibration are important advantages. Numerous experiments with helicopter rotors were conducted to demonstrate the potential for load reduction. Multiple stress states that arise when the blade shape is adapted await investigation. High aerodynamic efficiency, a relatively simple design and low weight make an integration of intelligent material structures and the blade design to extend the life and improve efficiency the next stage in 
the development. The authors of the paper [2] highlight the existing compromise in the aircraft wings, which makes the performance under various conditions always sub-optimal. Changing the geometry reduces these designing compromises. Formerly, it involved additional load, complexity and costs but intelligent materials can overcome these inconveniencies. Morphing is a technology, inspired by nature, dedicated to the next generation of aircraft. Unmanned aerial vehicles can provide a safe platform for testing intelligent materials which are becoming increasingly popular $[7,20,25]$. The works $[28,29]$ present the preliminary results of the tests of the main rotor designed to be integrated with the blades with a variable blade setting angle.

Although there have been many interesting studies and concepts, only a few aircraft using intelligent materials have been tested in a wind tunnel and even fewer have actually flown. In order to improve the aircraft performance, an alternative to morphing is to improve the propulsion systems. Despite the fact that internal combustion engines are displaced by hybrid solutions in the automotive industry, new or improved propulsion systems, e.g. Diesel engines [4], SI engines [10, 11] or Wankel engines [27] are still being tested in aviation. Furthermore, the publication [3] presents the results of research on the optimization of the wing and blade structures with active elements. The authors also referred to the studies describing the results of testing some concepts, e.g. envelope extension, increased lifting capacity or improved laminar flow. The common part of these investigations was to keep the structure stiff enough not to reduce its strength and flexible enough to modify its geometry. The paper [33] presents the research on the active control of the rotor designed for UAV aircraft. The rectangular rotor blades showing a linear twisting of $10^{\circ}$ and with 24 actuators with active composite fiber were tested. The aim of the study was to analyze how the generated vibrations and noise are impacted by the active control of the rotor. The results show that the applied solution obviously influences the improvement of the rotor stability and performance, as well as the active blade tracking. The authors of the paper [30] present an interesting overview of the previous research on the aircraft wing that changes its shape by means of the built-in actuators, e.g. electric, shape memory, piezoelectric. The author of the paper [31] suggests that the materials which have gained in importance in aviation are fiber-metal laminates, intelligent shape memory materials and piezoelectric materials. This paper emphasizes the most important role of the composites with builtin intelligent elements in monitoring a structure condition and in controlling its properties as well as the necessity of cooperation between $R \& D$ centers and the aviation industry in this field. The application of piezoelectric materials to manufacture simple elements is under control, but their incorporation into a larger composite structure is still a subject of research. Aircraft dimensions and their complexity influence, among others, the possibilities of applying a particular solution. On the basis of this review, it can be concluded that mainly piezoelectric and intelligent materials are being considered for the aviation applications. The obtained results will enable to develop a blade susceptible to twisting by embedding intelligent materials to reduce the force required to change the blade shape and prevent the blade itself from being damaged when changing the twist angle along the rotor radius.

\section{MATERIALS AND METHODS}

The tested object is an unmanned aircraft rotor blade. Ultimately, its shape will be possibly changed by using intelligent materials. The modified parameter will be the geometric blade setting angle. The blade with an active control of the blade twist angle should show a reduced stiffness compared to the standard solutions. Figure 1 shows a model of the blade with the identified applied aerodynamic aerofoils. There is an approximation of one aerofoil to another by the multisection solid function between each section.

The blade is based on three different NACA aerofoils which are approximated between the characteristic cross-sections as a modification of two adjacent aerofoils. Therefore, it is important to determine the transition characteristics for the derivative aerofoils between the main ones. The tested blade is divided into sections with the length of $100 \mathrm{~mm}$. The first section, at the blade fixing, is shorter and represents the resultant value. Figure 2 shows the blade view with its section marked. There are 8 separate sections used for the studies. The length of each section is selected to match the estimated aerodynamic forces to the size of the wind tunnel measurement space and the range of the aerodynamic scale. 


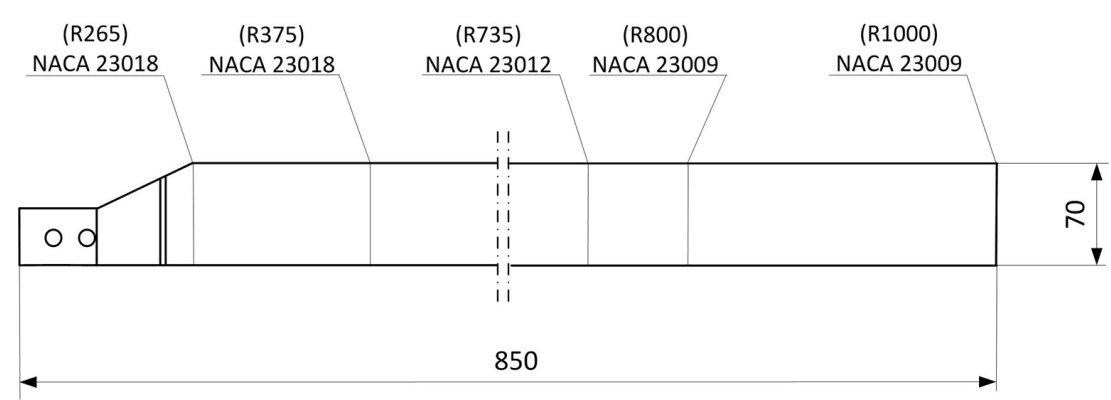

Fig. 1. Blade with the selected aerofoils

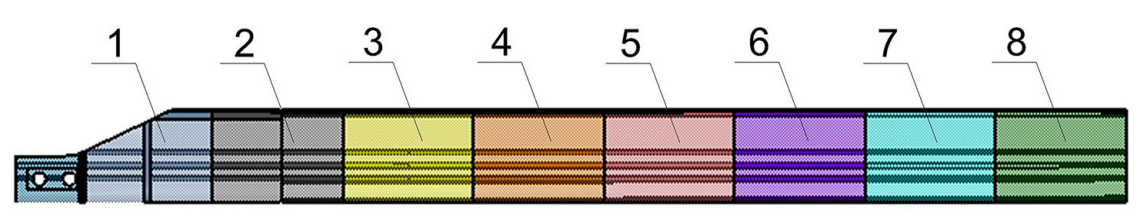

Fig. 2. Blade in sections

The GUNT HM 170 open-circuit wind tunnel with a closed measuring space was used for the research. This configuration causes limitations due to the interference with the walls of the wind tunnel and the horizontal pressure gradient $\mathrm{dp} / \mathrm{dx}$. The advantages of this measuring system include reduced pressure pulsation and lower flow resistance. Table 1 shows the basic parameters specific to the wind tunnel. Figure 3 shows the view of the test stand.

A wind tunnel is a classic device for flow testing in aerodynamic experiments $[18,26$, 34]. The tested object remains stable during air movement. The desired flow is generated around the object. The GUNT HM 170 is an open wind tunnel to measure the aerodynamic parameters of different models. The maximum air velocity that can be achieved in an open wind tunnel is

Table 1. Parameters of the GUNT HM 170 wind tunnel

\begin{tabular}{|l|l|}
\hline \multicolumn{1}{|c|}{ Parameter } & \multicolumn{1}{c|}{ Value } \\
\hline $\begin{array}{l}\text { Flow cross-section } \\
\text { (width } x \text { height) }\end{array}$ & $292 \times 292 \mathrm{~mm}$ \\
\hline Length & $450 \mathrm{~mm}$ \\
\hline Maximum velocity of wind & $28 \mathrm{~m} / \mathrm{s}$ \\
\hline Pressure difference & $500 \mathrm{~Pa}$ \\
\hline Maximum volumetric flow & $9000 \mathrm{~m} / \mathrm{h}$ \\
\hline Power of the electric engine & $2.25 \mathrm{~kW}$ \\
\hline Maximum fan velocity & $2850 \mathrm{obr} / \mathrm{min}$ \\
\hline Force measurement range & $0 . .5 \mathrm{~N}$ and $0 . . .10 \mathrm{~N}$ \\
\hline
\end{tabular}

$28 \mathrm{~m} / \mathrm{s}$. The wind tunnel is equipped with a twocomponent aerodynamic scale.

Figure 4 shows the wind tunnel measurement area prepared for testing. There is the sensor of the thermoanemometer mounted on the extension arm and placed in the working space, in front of the examined blade section. The thermoanemometer module ATU 08 is used in the tests (Figure 5). Thermoanemometric study is an indirect method of measuring the flow velocity of gases by calculating the heat loss of the warmed element placed in the tested flow. The sensor measuring element is a fiber of several micrometers in diameter, made of a temperature-dependent resistance material. Electric current heats up the fiber, so its temperature is measured simultaneously. The ATU 08 four-channel eight-path constant-temperature and direct-current module is designed for precise laboratory measurements of speed and temperature in air flows [19].

The test stand enables: measurement of air flow velocity, adjustment of the angle of attack, measurement of the lift and drag forces as well as measurement of the ambient air temperature. The aerodynamic forces were measured using a two-component aerodynamic balance, which is part of the wind tunnel equipment. The balance is used to measure the components of forces parallel and perpendicular to the direction of air flow. The method of forces measurement on an aerofoil as a function of angle of attack is shown in Figure 6. 


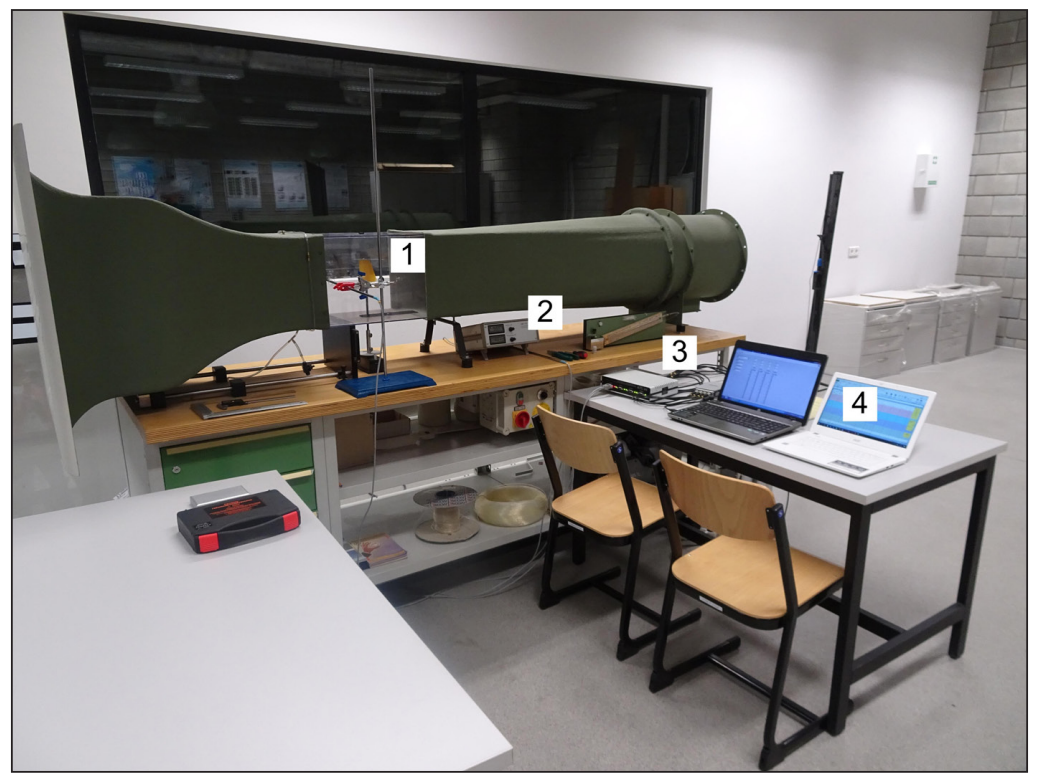

Fig. 3. Test bench: 1 - measurement space, 2 - scales display, 3 - thermoanemometric module, 4 - computer with a data recording device

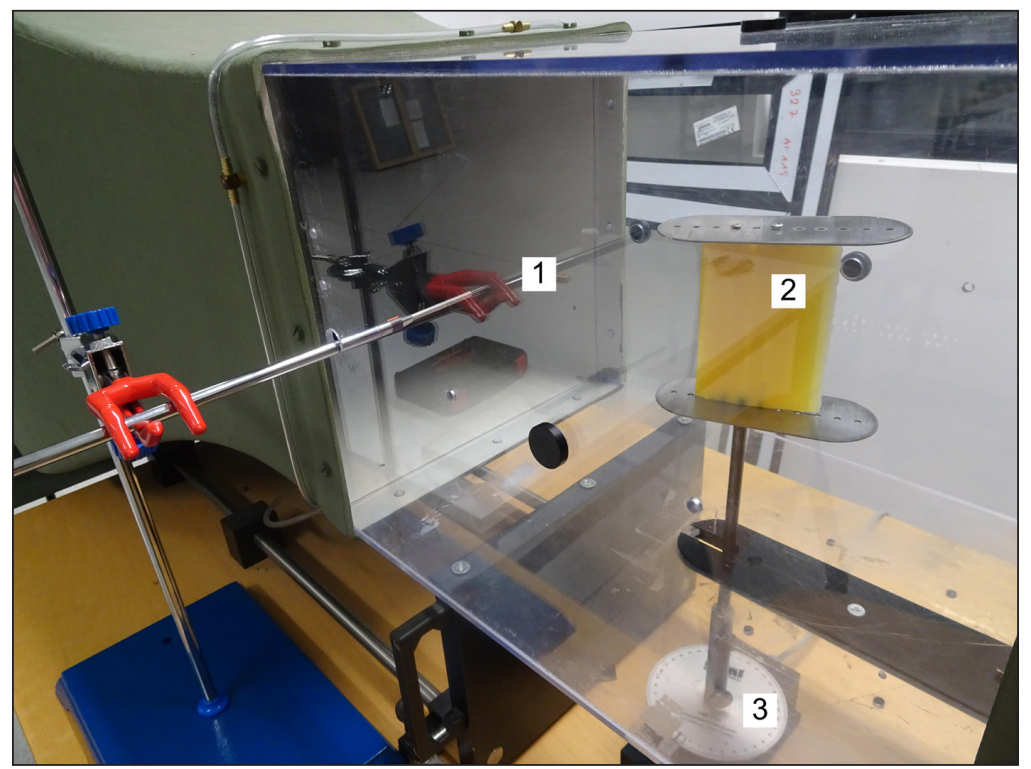

Fig. 4. Measurement area: 1 -thermoanemometer, 2 - tested blade section, 3 - aerodynamic scale

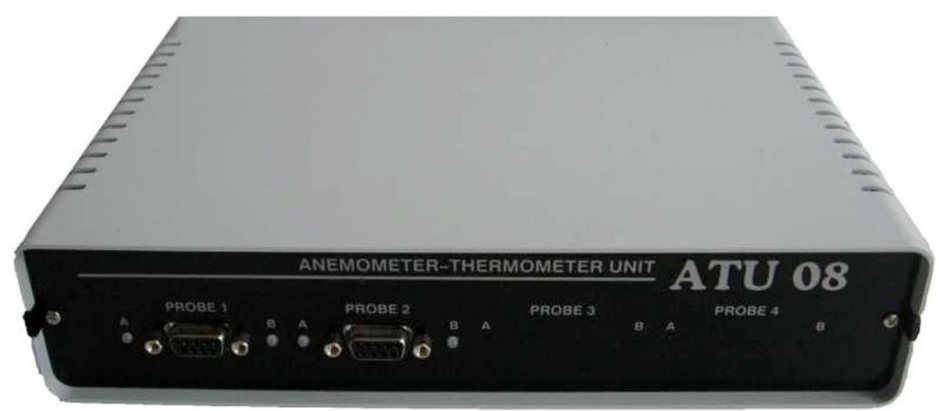

Fig. 5. ATU 08 module [19] 


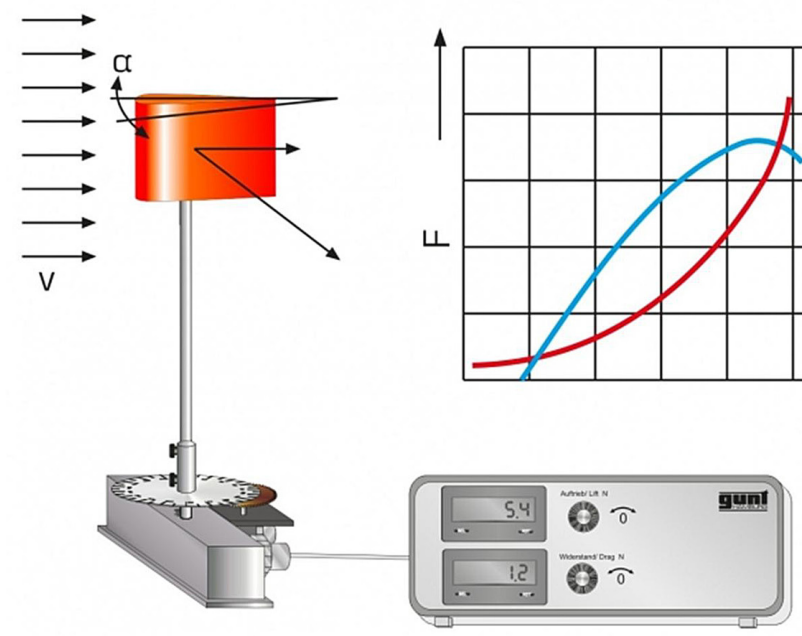

Fig. 6. Measurement of the lift and drag forces on an aerofoil as a function of angle of attack [13]
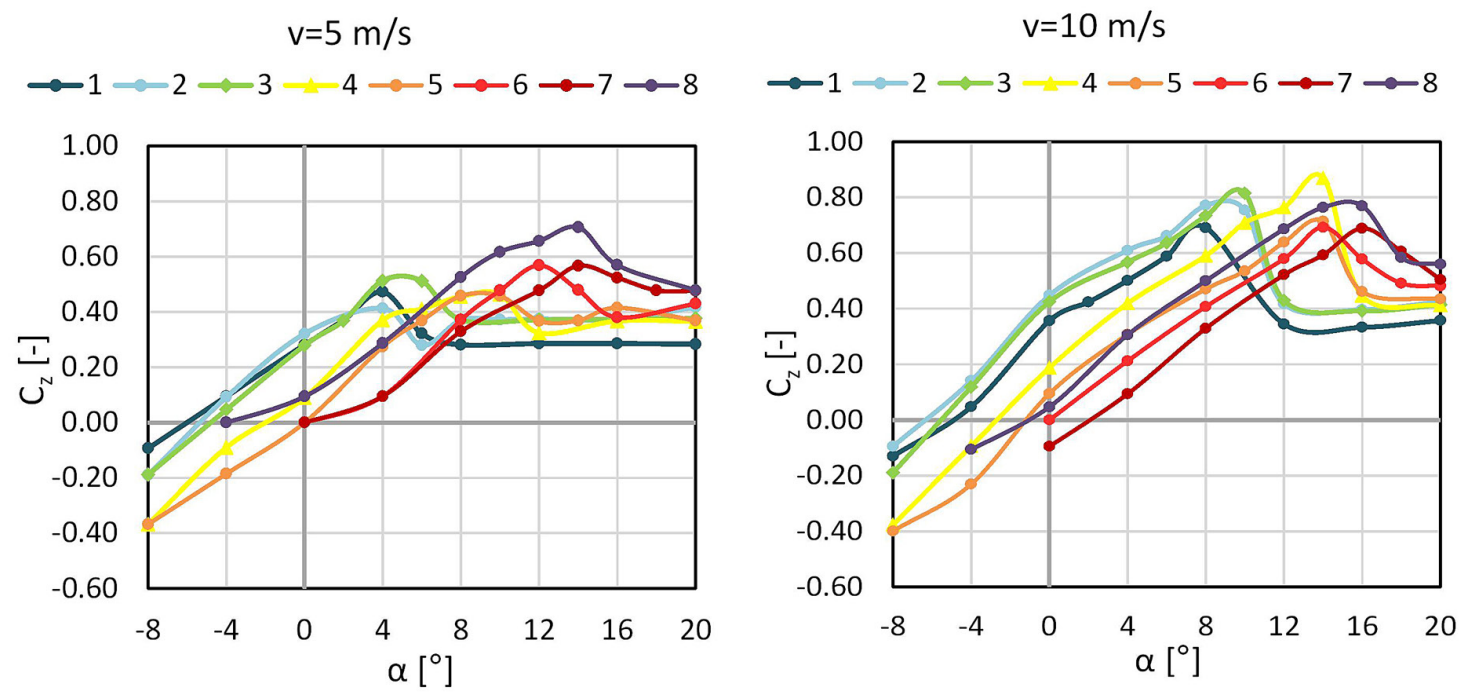

$\mathrm{v}=15 \mathrm{~m} / \mathrm{s}$

$\mathrm{v}=20 \mathrm{~m} / \mathrm{s}$

$\rightarrow 1 \multimap-2 \multimap 3-4 \multimap-5 \multimap 6 \rightarrow 7 \multimap 8$

$\rightarrow-1 \multimap 2 \multimap 3-4 \rightarrow 5 \rightarrow 6 \rightarrow 7 \rightarrow-8$
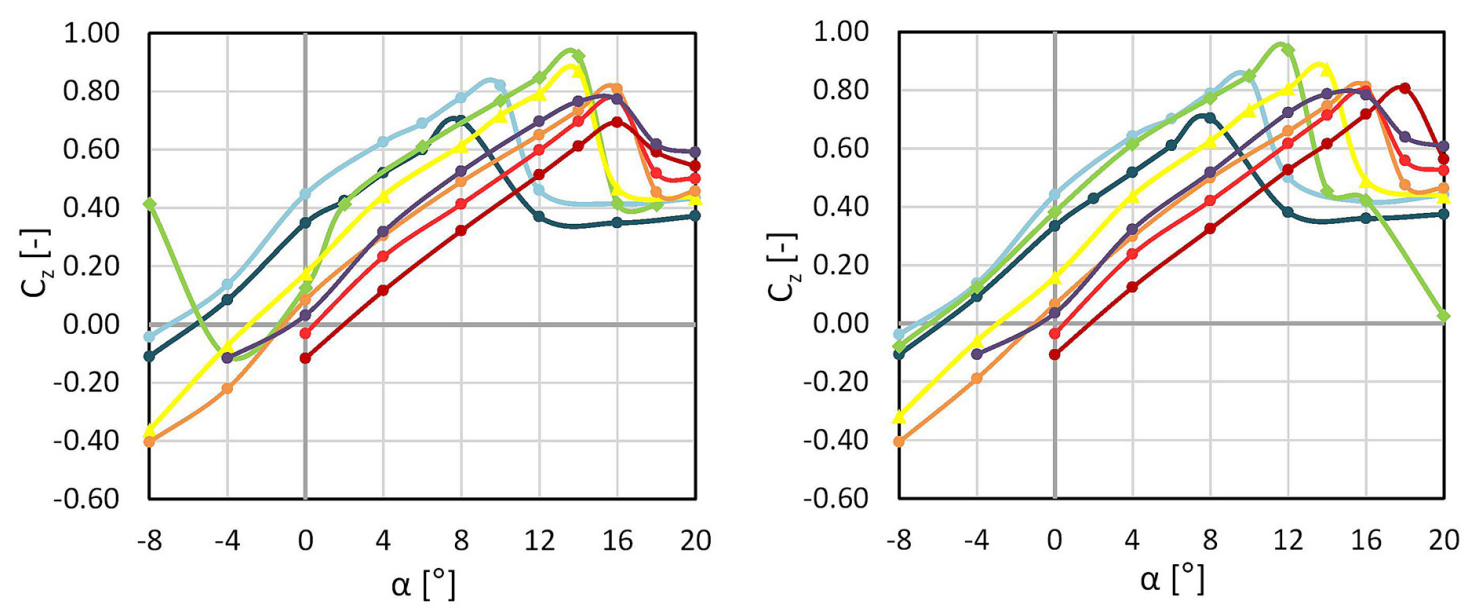

Fig. 7. Lift force coefficient for all velocities 


\section{RESULTS}

The correlation between the lift force coefficient and the angle of attack for all the tested velocities is shown in Figure 7. The values of the coefficients were determined with reference to the angle of attack $\alpha$ the value of which - amounting to 0 - corresponds to the initial position for the tested blade. The impact of the angle of attack on the lift force coefficient for eight examined blade sections at four air flow velocities is presented. The highest value of $\mathrm{Cz}$ at the air flow velocity $\mathrm{v}=5 \mathrm{~m} / \mathrm{s}$ was obtained for section 8 at the angle of attack $\alpha=14^{\circ}$. Sections 1 to 8 reach their maximum values for the angles: $4^{\circ}, 4^{\circ}, 6^{\circ}, 10^{\circ}, 10^{\circ}$, $12^{\circ}, 14^{\circ}, 14^{\circ}$. The highest $\mathrm{Cz}$ value at the air flow velocity $\mathrm{v}=10 \mathrm{~m} / \mathrm{s}$ was obtained for section 4 at the angle of attack $\alpha=14^{\circ}$. The sections reach their maximum values for the angles: $8^{\circ}, 8^{\circ}, 10^{\circ}$,

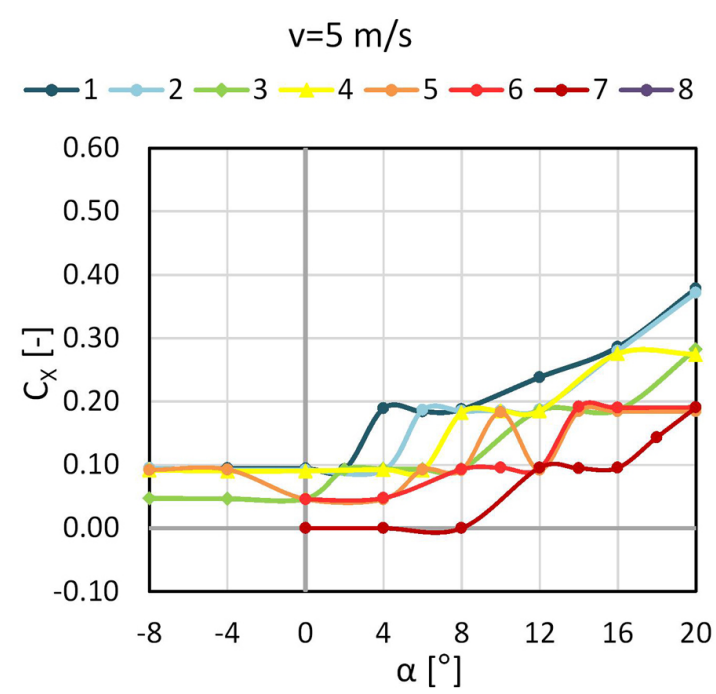

$v=15 \mathrm{~m} / \mathrm{s}$

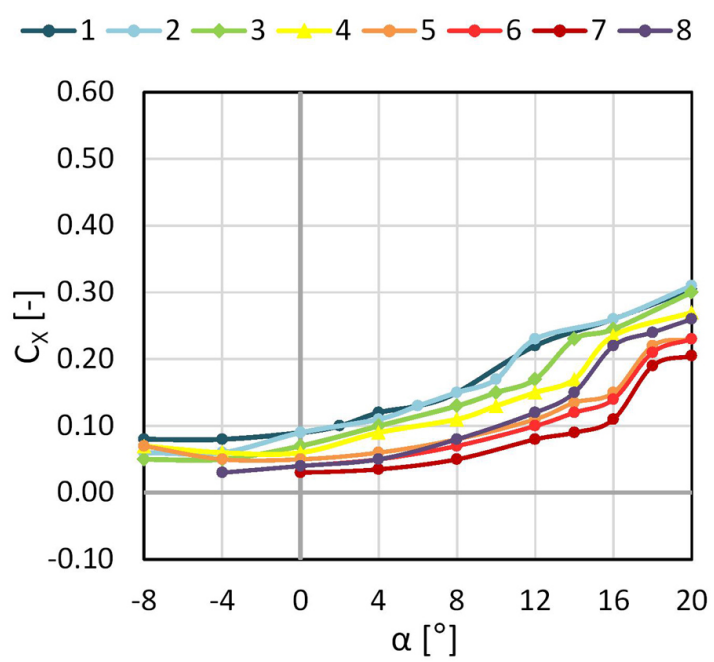

$14^{\circ}, 14^{\circ}, 14^{\circ}, 16^{\circ}, 16^{\circ}$. The highest $\mathrm{Cz}$ value at $\mathrm{v}=15 \mathrm{~m} / \mathrm{s}$ was obtained for section 3 at the angle of attack $\alpha=14^{\circ}$. The sections reach their maximum values for the angles: $8^{\circ}, 10^{\circ}, 14^{\circ}, 14^{\circ}, 16^{\circ}$, $16^{\circ}, 16^{\circ}, 16^{\circ}$. The highest value of $\mathrm{Cz}$ for velocity $\mathrm{v}=20 \mathrm{~m} / \mathrm{s}$ was obtained for section 3 at the angle of attack equal to $\alpha=12^{\circ}$. The sections reach their maximum values for the angles: $8^{\circ}, 10^{\circ}, 12^{\circ}, 14^{\circ}$, $16^{\circ}, 16^{\circ}, 18^{\circ}, 16^{\circ}$.

Figure 8 illustrates the correlation between the drag force coefficient and the blade twist angle for all the analyzed velocities. The highest drag force coefficient was found in each case for the first section which includes the blade head. Section 7 has the lowest drag force coefficient for all of the examined velocities and angles of attack. It is worth pointing out that for velocity $\mathrm{v}=10 \mathrm{~m} / \mathrm{s}$, the drag force coefficient did not exceed 0.15 at any time. Basically, as the angle of attack increases,
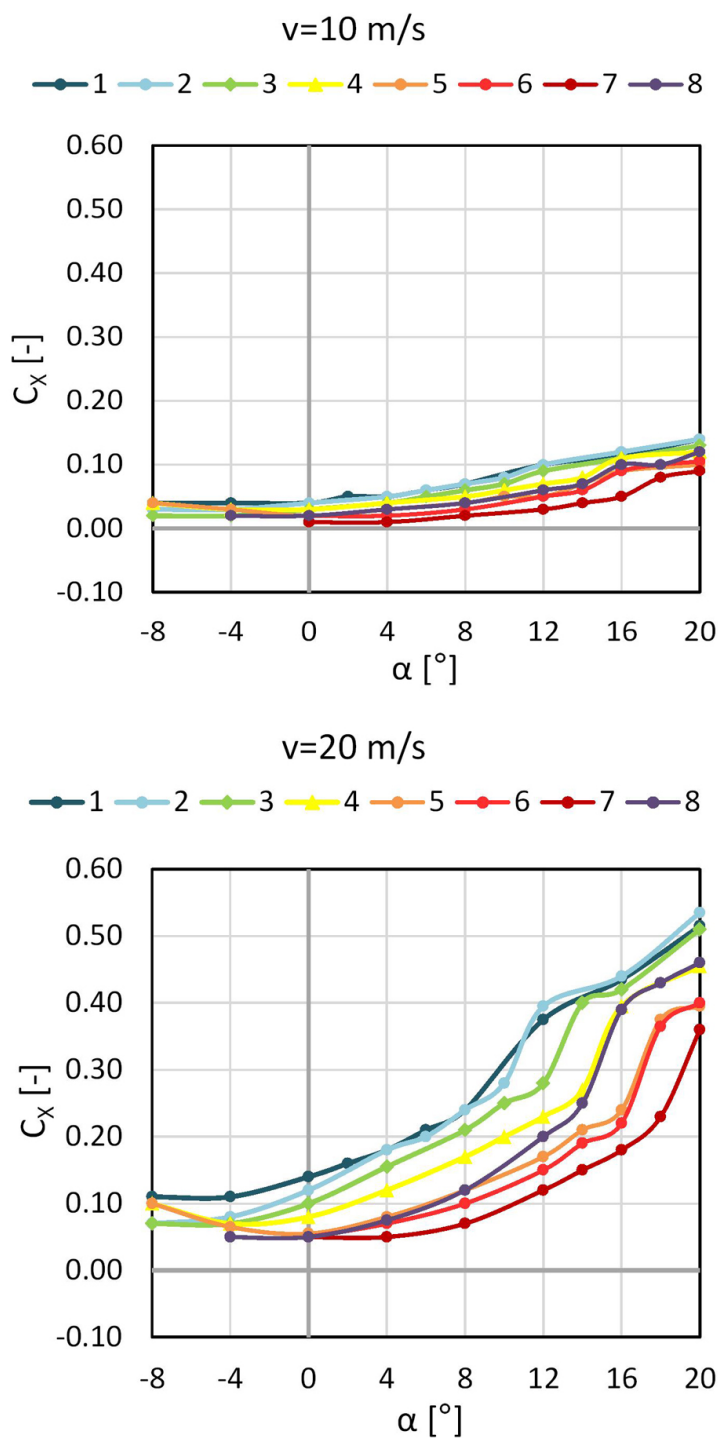

Fig. 8. Drag force coefficient for all velocities 
the value of drag force coefficient also becomes higher. The change of the drag force coefficient is irregular for velocity $v=5 \mathrm{~m} / \mathrm{s}$. The change is too little to be measured with the balance.

Figure 9 presents the influence of airflow velocity on the characteristics of the lift force coefficient $\mathrm{Cz}$ as a function of the angle of attack. The characteristics were performed for each of the examined blade sections. The increase in the airflow velocity is accompanied by the increase in the angle of attack at which the maximum value of $\mathrm{Cz}$ occurs. The highest values of $\mathrm{Cz}$ occur at the higher airflow velocities.

Figure 10 illustrates the impact of airflow velocity on the characteristics of the drag force coefficient as a function of the angle of attack. The experimentally determined characteristics are presented for each of the examined blade sections. Basically, as the angle of attack increases, the value of drag force coefficient also becomes higher. The change of the drag force coefficient is irregular for the smallest analyzed velocity $\mathrm{v}=5 \mathrm{~m} / \mathrm{s}$. The drag force coefficient is lower at the higher air flow velocities in a given range of angles of attack. For blade sections 1-4, the drag force coefficient takes the lowest values in the range of $-8 \div 0^{\circ}$. In the following sections (5 to 8), the lowest values are taken in the range of $-4 \div 4^{\circ}$. The drag force coefficient in these ranges does not exceed 0.10 in each section. The lowest values of the drag force coefficient within the analyzed range of angles of attack were achieved in section 7. The largest ones are found in sections 1 and 2 and exceed the values of 0.3 for the angle of attack of $20^{\circ}$.

A sample analysis of the drag force coefficient was conducted for section 3 . Figure 11 shows the functions approximating the correlation of the drag force coefficient and the blade twist angle for the specific velocities and the equations describing them. The second degree polynomial was appropriate in each case. Except for the lowest air
1

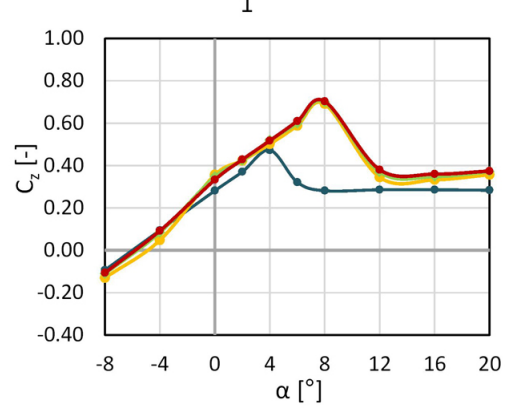

4

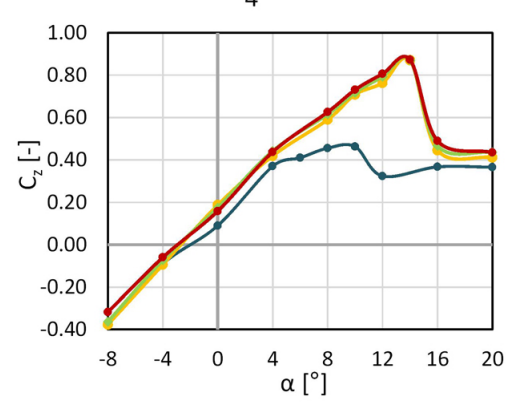

7

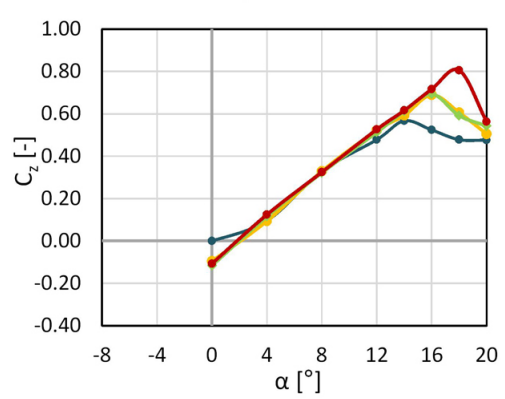

2

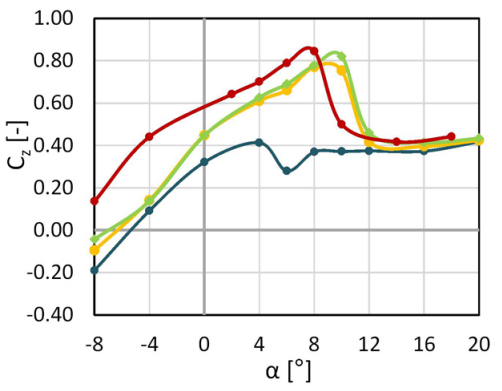

5

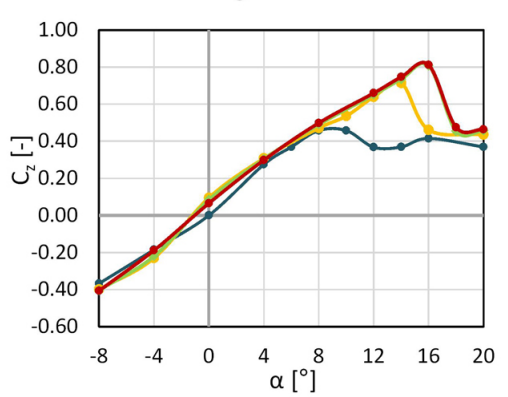

8

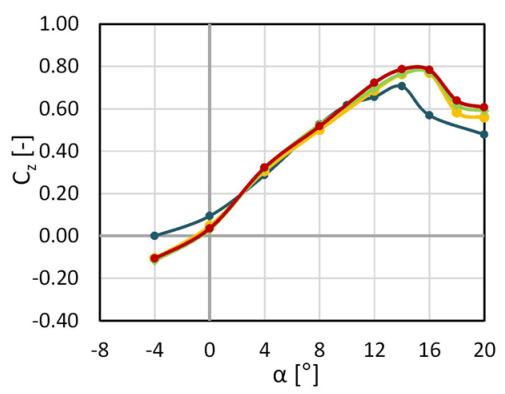

3
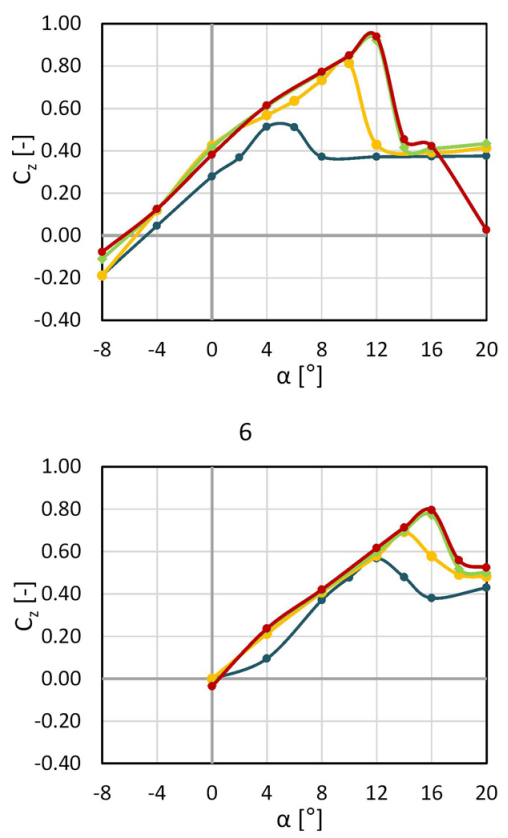

Fig. 9. Lift force coefficient for all sections 


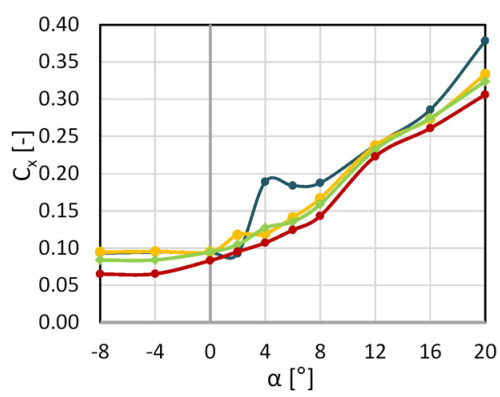

4
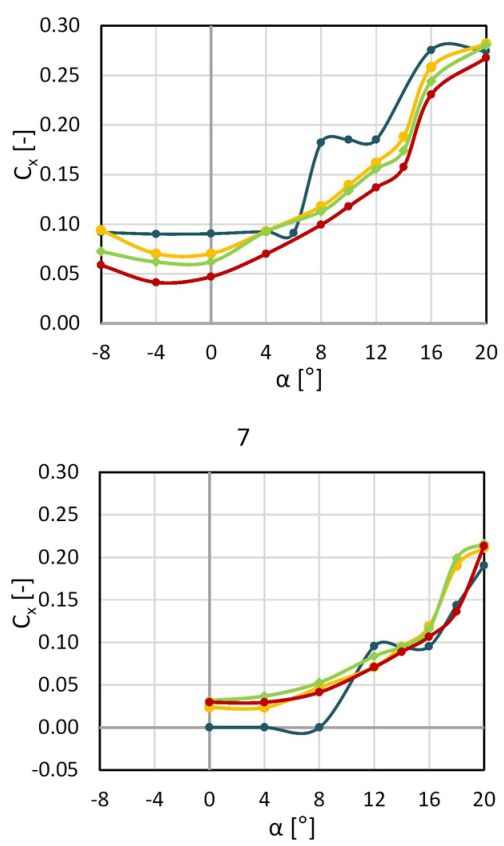

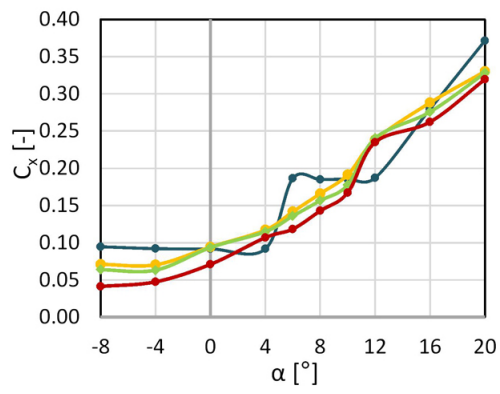

5

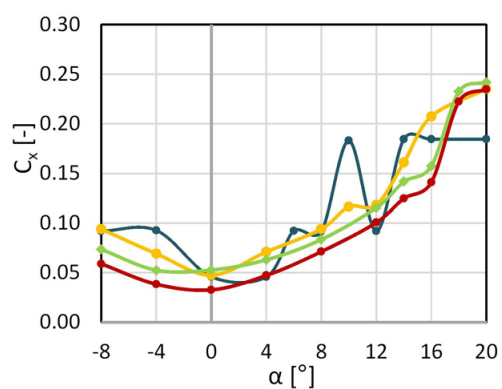

8

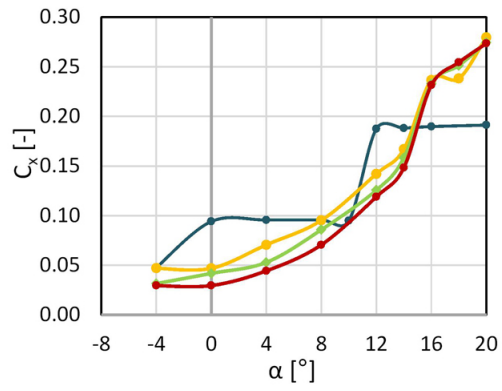

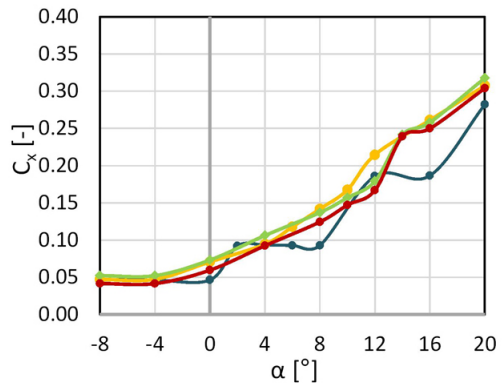

6

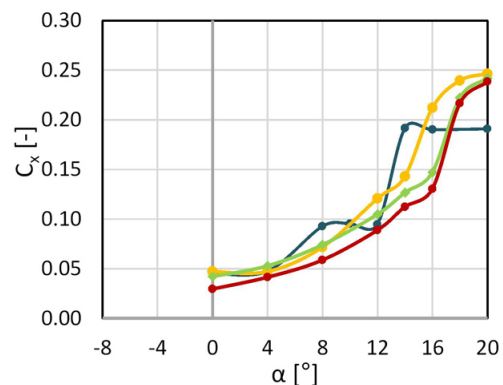

Fig. 10. Drag force coefficient for all sections

flow velocity at which irregular courses were obtained, the lowest drag force coefficient value was obtained for the highest velocity. This trend appears in most of the examined sections.

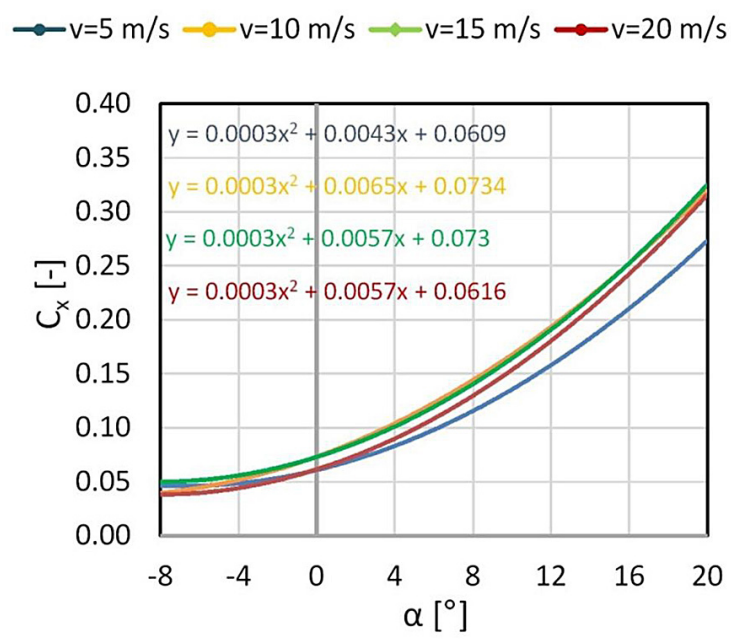

Fig. 11. Functions approximating the correlation between drag force coefficient and angle of attack
An important parameter informing about aircraft performance is the lift-to-drag ratio $\mathrm{k}$ which is determined from the formula:

$$
\mathrm{k}=\mathrm{Cz} / \mathrm{Cx}
$$

where: $C z$ and $C x-$ aerodynamic coefficients of the lift force and drag.

For the optimum angle of attack, the maximum lift-to-drag ratio is achieved. This property is specified for the designed main rotor blade by determining the lift-to-drag ratio $\mathrm{k}$ for particular blade sections and four wind tunnel airflow velocities (Figure 12). For $\mathrm{v}=5 \mathrm{~m} / \mathrm{s}$, the value of $\mathrm{k}=6$ was exceeded in section 8 only; at $\mathrm{v}=10 \mathrm{~m} / \mathrm{s}$, the maximum value of 7.33 was achieved in section 7. For $v=15 \mathrm{~m} / \mathrm{s}$, the lift-to-drag ratio deteriorated but homogeneous results were obtained for $\mathrm{k}=5 \div 7$ in all the sections, except the initial ones, in the range $4 \div 16^{\circ}$ of the angle of attack. The highest lift-to-drag ratio, i.e. $\mathrm{k}=7 \div 8$ was achieved at $\mathrm{v}=20 \mathrm{~m} / \mathrm{s}$ for sections $6 \div 8$. 

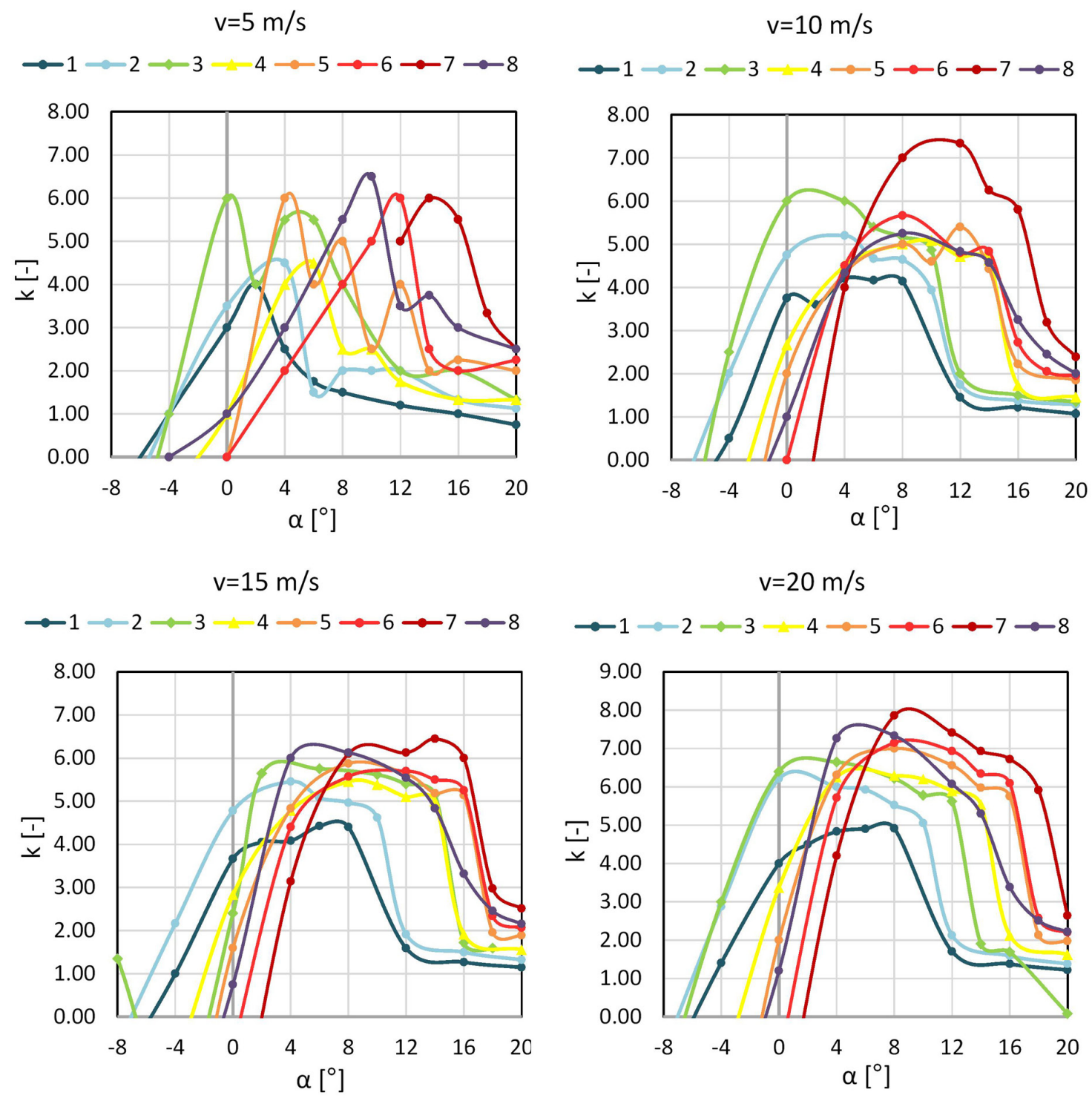

Fig. 12. Lift-to-drag ratio for all velocities

\section{CONCLUSIONS}

The individual sections show noticeable differences in the aerodynamic coefficients due to a different blade twist angle along the blade length. By treating the zero blade angle position as a reference for particular sections, the most favorable setting for the entire blade can be specified. Theoretically, in order to achieve the greatest lift force, the blade should be twisted so that its individual positions would be at these angular settings. While analyzing the obtained results, it can be observed that for the same air flow velocity, the highest lift force is generated by section 3 for $\alpha=12^{\circ}$.

The lowest value is generated by section 1 because this section is the part of the blade connected to the head and does not generate the lift force so effectively over its entire length. The blade tips are based on aerofoils which also exhibit deteriorated properties compared to the best section. Section 1 generates $25 \%$ lesser lift force than section 3 , while section 8 generates $16 \%$ lesser lift force than the best section 3. Actually, the position according to the maximum lift force is not necessarily required at this stage due to the aero-elasticity of blades under real conditions. The tip cross-sections of the blade reach their optimum for higher angles of attack due to the aerodynamic forces, inertia forces and elastic reactions of the overflown blade. They will be deformed during operation, which will lead to an increase in their angle of attack relative to the initial position. 


\section{Acknowledgements}

This work has been financed by National Centre for Research and Development under the LIDER program. Grant Agreement No. LIDER/45/0177/L-9/17/NCBR/2018.

\section{REFERENCES}

1. Ajaj R.M., Beaverstock C.S., and Friswell M.I. Morphing aircraft: The need for a new design philosophy. Aerospace Science and Technology, 49, 2016, 154-166.

2. Barbarino S., Bilgen O., Ajaj R.M., Friswell M.I. and Inman D.J. A Review of Morphing Aircraft. Journal of Intelligent Material Systems and Structures, 22(9), 2011, 823-877.

3. Coutu D., Brailovski V., and Terriault P. Optimized design of an active extrados structure for an experimental morphing laminar wing. Aerospace Science and Technology, 14, 2010, 451-458.

4. Czyż Z., Siadkowska K., and Sochaczewski R. CFD Analysis of Charge Exchange in an Aircraft Opposed-Piston Diesel Engine. MATEC Web of Conferences, 252, Lublin, Poland 2019, 04002.

5. Daynes S. and Weaver P.M. A morphing trailing edge device for a wind turbine. Journal of Intelligent Material Systems and Structures, 23(6), 2012, 691-701.

6. Epps J.J. and Chopra I. In-flight tracking of helicopter rotor blades using shape memory alloy actuators. Smart Materials and Structures, 10(1), 2001.

7. Es-Souni M., Wassel E., Dietze M., Laghrissi A., Klöhn F., Weyrich, T. and Es-Souni M. Processing of nanotubes on NiTi-shape memory alloys and their modification with photografted anti-adhesive polymer brushes. Towards smart implant surfaces. Materials and Design, 182, 2019, 108031.

8. Fincham J.H.S. and Friswell M.I. Aerodynamic optimisation of a camber morphing aerofoil. Aerospace Science and Technology, 43, 2015, 245-255.

9. Fortini A., Suman A., Merlin M. and Garagnani G.L. Morphing blades with embedded SMA strips: An experimental investigation. Materials and Design, 85, 2015, 785-795.

10. Grabowski Ł., Czyż Z. and Kruszczyński K. Numerical Analysis of Cooling Effects of a Cylinders in Aircraft SI Engine. SAE Technical Paper, 2014, 2014-01-2883.

11. Grabowski Ł., Siadkowska K. and Skiba K. Simulation Research of Aircraft Piston Engine Rotax 912. MATEC Web of Conferences, 252, Lublin, Poland 2019, 05007.

12. Hintz C., Torno C. and Garcia Carrillo L.R. De- sign and dynamic modeling of a rotary wing aircraft with morphing capabilities. Conference Proceedings of 2014 International Conference on Unmanned Aircraft Systems, USA, Orlando, 2014, 492-498.

13. HM 170 Open wind tunnel. https://www.gunt.de (accessed on 5 April 2020).

14. Keshmiri S., Kim A.R., Shukla D., Blevins A. and Ewing M. Flight Test Validation of Collision and Obstacle Avoidance in Fixed-Wing UASs with High Speeds Using Morphing Potential Field. Conference Proceedings of 2018 International Conference on Unmanned Aircraft Systems, USA, Dallas, 2018, 589-598.

15. Kessler C. Active rotor control for helicopters: Individual blade control and swashplateless rotor designs. CEAS Aeronautical Journal, 1, 2011, 23-54.

16. Kovalovs A., Barkanov E., Ruchevskis S. and Wesolowski M. Optimisation Methodology of a Full-scale Active Twist Rotor Blade. Procedia Engineering, 178, 2017, 85-95.

17. Lachenal X., Daynes S. and Weaver P.M. Review of morphing concepts and materials for wind turbine blade applications. Wind Energy, 16, 2013, 283-307.

18. Li B., Zhou W., Sun J., Wen C.Y. and Chen C.K. Development of model predictive controller for a tail-sitter VTOL UAV in hover flight. Sensors 18(9),2018, 1-21.

19. Ligęza P. ATU 08 Ośmiotorowy moduł stałotemperaturowo-stałoprądowy do pomiarów anemometryczno-termometrycznych. Instytut Mechaniki Górotworu PAN, 2009.

20. Mohd Jani J., Leary M., Subic A. and Gibson M.A. A review of shape memory alloy research, applications and opportunities. Materials and Design, 56, 2014, 1078-1113.

21. Niemi J.E. and Raghu Gowda B.V. Gyroplane Rotor Aerodynamics Revisited - Blade Flapping and RPM Variation in Zero-g Flight. 49th AIAA Aerospace Sciences Meeting including the New Horizons Forum and Aerospace Exposition, USA, Orlando 2011.

22. Pastrikakis V.A., Steijl R. and Barakos G.N. Effect of Active Gurney Flaps on Overall Helicopter Flight Envelope. Aeronautical Journal, 120(1230), 2016, 1230-1261.

23. Pastrikakis V.A., Steijl R., Barakos G.N. and Małecki J. Computational aeroelastic analysis of a hovering W3 Sokol blade with gurney flap. Journal of Fluids and Structures, 53, 2015, 96-111.

24. Rodgers J., Hagood N., Weems D., Rodgers J., Hagood N. and Weems, D. Design and manufacture of an integral twist-actuated rotor blade. 38th Structures, Structural Dynamics, and Materials 
Conference. American Institute of Aeronautics and Astronautics, 1997.

25. Saghaian S.M., Karaca H.E., Souri M., Turabi A.S. and Noebe R.D. Tensile shape memory behavior of Ni50.3Ti29.7Hf20 high temperature shape memory alloys. Materials and Design, 101, 2016, 340-345.

26. Shen J., Su Y., Liang Q. and Zhu X. Calculation and identification of the aerodynamic parameters for small-scaled fixed-wing UAVs. Sensors, 18(1), 2018, 1-18.

27. Siadkowska K., Wendeker M., Majczak A., Baranski G. and Szlachetka M. The Influence of Some Synthetic Fuels on the Performance and Emissions in a Wankel Engine. SAE Technical Papers, 2014, 2014-01-26.

28. Siadkowska K., Raczyński R. and Wendeker M. Numerical analysis of the rotor in the co-simulation methodology. IOP Conference Series: Materials Science and Engineering Paper, IV International Conference of Computational Methods in Engineering Science - CMES'19, Poland, Kazimierz Dolny, 2019, 710, 012009.

29. Skiba K. Designing and FEM simulation of the helicopter rotor and hub. IOP Conference Series: Materials Science and Engineering Paper, IV International Conference of Computational Methods in Engineering Science - CMES'19, Poland, Kazimierz Dolny, 2019, 710, 012003.

30. Sofla A.Y.N., Meguid S.A. Tan K.T. and Yeo W.K. Shape morphing of aircraft wing: Status and challenges. Materials and Design, 31, 2009, 1284-1292.

31. Surowska B. Functional and Hybrid Materials in Air Transport. Maintenance and Realibity, 3, 2008, 30-40.

32. Wilbur M.L., Mistry M.P., Lorber P.F., Blackwell R., Barbarino S., Lawrence T.H. and Arnold U.T.P. Rotary Wings Morphing Technologies: State of the Art and Perspectives. Morphing Wing Technologies, 2018, 759-797.

33. Wilbur M.L. and Wilkie W.K. Active-twist rotor control applications for UAVs. Transformational Science and Technology for the Current and Future Force, 2006, 185-192.

34. Yao X., Liu W., Han W., Li G. and Ma Q. Development of Response Surface Model of Endurance Time and Structural Parameter Optimization for a Tailsitter UAV. Sensors, 20(6), 2020, 1766. 